\title{
The Combined Development of Marble Fields in the Conditions of Siberia
}

\author{
Michael Y. Kaderov* and Alexander I. Kosolapov \\ Siberian Federal University \\ 79 Svobodny, Krasnoyarsk, 660041, Russia
}

Received 11.11.2014, received in revised form 16.12.2014, accepted 19.01.2015

The features of the development of the marble deposits in the harsh climatic conditions and proved the feasibility of seasonal work career. To provide the required volumes of blocks and full-time staff proposed in such conditions the development of marble deposits carry a combined way. Justified the duration of the season of the mine and technological schemes of opening a mine field during mining operations. It is proved that seasonal work career with a year-round operation of the mine improves the efficiency of investment in mining marble in 1.9-2.3 times.

Keywords: the combined development, fields of facing marble, severe climatic conditions, seasonality of open and underground works.

\section{Комбинированная разработка мраморных месторождений в условиях Сибири}

\author{
М.Ю. Кадеров, А.И. Косолапов \\ Сибирский федеральный университет \\ Россия, 660041, Красноярск, пр. Свободньій, 79
}

Исследованы особенности разработки мраморных месторождений в суровых климатических условиях и доказана иелесообразность сезонной работы карьеров. Для обеспечения требуемых объемов добычи блоков и полной занятости персонала предложено в подобных условиях разработку мраморных месторождений вести комбинированным способом. Обоснована продолжительность сезона работы карьера и составлены технологические схема вскрытия шахтного поля при ведении горных работ. Доказано, что сезонная работа карьера при круглогодичной работе шахты повышает эффективность инвестиций в разработку месторождений мрамора в 1,9-2,3 раза.

Ключевые слова: комбинированная разработка, месторождения обличовочного мрамора, суровые климатические условия, сезонность открытых и подземных работ.

(c) Siberian Federal University. All rights reserved

* Corresponding author E-mail address: kaderov@list.ru 
Опыт работы многих горнорудных предприятий доказал эффективность комбинированной разработки. При этом способе разработки сочетаются открытые и подземные горные работы на одном или нескольких сближенных участках месторождения во времени и пространстве с последовательным переходом от одних к другим или одновременным их производством. Причем граница между открытыми и подземными работами и предопределяет эффективность разработки месторождения в целом.

Применение комбинированного способа разработки мраморных месторождений в обычных условиях позволяет снизить затраты на вскрышные работы и ускорить ввод предприятия в работу, а в условиях Сибири - снизить их влияние на формирование термических напряжений [1] при отрицательных температурах воздуха [2].

Поскольку напряжения в массиве связаны со скоростью прохождения упругих волн через него, то, измеряя последние, можно определять напряженное состояние и характер его временной и пространственной динамики.

Исследования $[1,3]$ доказали, что выход блоков зависит от напряженного состояния массива и его временной динамики, связанной с глубиной разработки, расположением участка и вариацией температур воздуха, а следовательно, и от температуры мрамора.

Влияние климатических факторов на режим работы мраморных карьеров показано на примере Кибик-Кордонского месторождения мрамора, которое расположено на юге Хакасии, в северных отрогах Западного Саяна, где минимальная температура воздуха в декабре-январе и достигает минус $37-55^{\circ} \mathrm{C}$, а максимальная $34-55^{\circ} \mathrm{C}$ - в июле. В этих условиях существенное влияние на эффективность разработки месторождения оказывает временное и пространственное изменение температуры поверхности мрамора, соответствующим образом влияющее на вариацию термических напряжений в мраморе и выход блоков $[1,3]$. При разработке месторождения круглогодично карьером с использованием камнерезных машин с алмазными режущими элементами (канатных пил) зимой технологическая вода замерзает, образуя наледи, а во время их интенсивного таяния объем талых вод значительно превышает технические нужды карьера и большая часть воды поступает в окружающую среду, ухудшая экологическую ситуацию. Это и предопределяет сезонность ведения открытых горных работ и необходимость перехода на комбинированную технологию разработки месторождения.

Для оценки влияния температуры поверхности мрамора на напряжения в массиве изучена динамика температуры мрамора и скорости прохождения упругих волн на участке «Южный» Кибик-Кордонского месторождения мрамора (рис. 1). Результаты замера температуры мрамора и воздуха представлены в табл. 1, а скорости упругих волн - на рис. 2.

Из графика (рис. 2) следует, что скорость упругих волн значительнее варьирует в марте, когда мрамор на глубине 3-4 м имеет отрицательную температуру, а на поверхности (днём) положительную (табл. 1). За счет этого скорости упругих волн, а следовательно, и термические напряжения [5] более заметно варьируют в пространстве (графики 1, 2 на рис. 2). Эти данные и опыт разработки месторождения свидетельствуют о том, что для увеличения выхода блоков и улучшения их качества добычные работы желательно вести только при определенных температурах воздуха.

Для обоснования продолжительности сезона открытых работ исследовали изменение температуры поверхности мрамора в карьере и в шахте в разное время года.

$$
-209-
$$




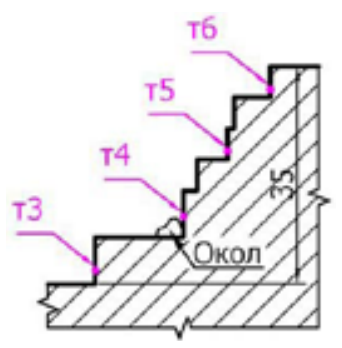

Рис. 1. Места замеров скорости упругих волн и температуры поверхности мрамора на участке «Южный» Кибик-Кордонского месторождения мрамора

Таблица 1. Результаты замеров температуры мрамора и воздуха

\begin{tabular}{|c|c|c|c|c|c|c|}
\hline \multirow{2}{*}{ Точка замера } & \multicolumn{5}{|c|}{ Дата и время проведения замеров } \\
\cline { 2 - 7 } & \multicolumn{2}{|c|}{$9.03 .2007 / 13.30$} & \multicolumn{2}{|c|}{$10.03 .2007 / 05.30$} & \multicolumn{2}{c|}{$14.05 .2007 / 12.00$} \\
\cline { 2 - 7 } & $\mathrm{t}_{\mathrm{m}},{ }^{\circ} \mathrm{C}^{*}$ & $\mathrm{t}_{\mathrm{B}},{ }^{\circ} \mathrm{C}^{*}$ & $\mathrm{t}_{\mathrm{m}},{ }^{\circ} \mathrm{C}$ & $\mathrm{t}_{\mathrm{B}},{ }^{\circ} \mathrm{C}$ & $\mathrm{t}_{\mathrm{m}},{ }^{\circ} \mathrm{C}$ & $\mathrm{t}_{\mathrm{B}},{ }^{\circ} \mathrm{C}$ \\
\hline 3 & 4,2 & 12,0 & $-6,0$ & $-4,0$ & 12,8 & 24,0 \\
\hline 4 & 9,0 & 6,0 & $-6,0$ & $-4,0$ & 12,0 & 20,0 \\
\hline 5 & 9,0 & 5,0 & $-6,0$ & $-4,5$ & 16,5 & 19,0 \\
\hline 6 & 1,0 & 5,0 & $-10,0$ & $-5,0$ & 8,5 & 14,0 \\
\hline
\end{tabular}

${ }^{*} \mathrm{t}_{\mathrm{M}} ; \mathrm{t}_{\mathrm{B}}-$ температура мрамора и воздуха.

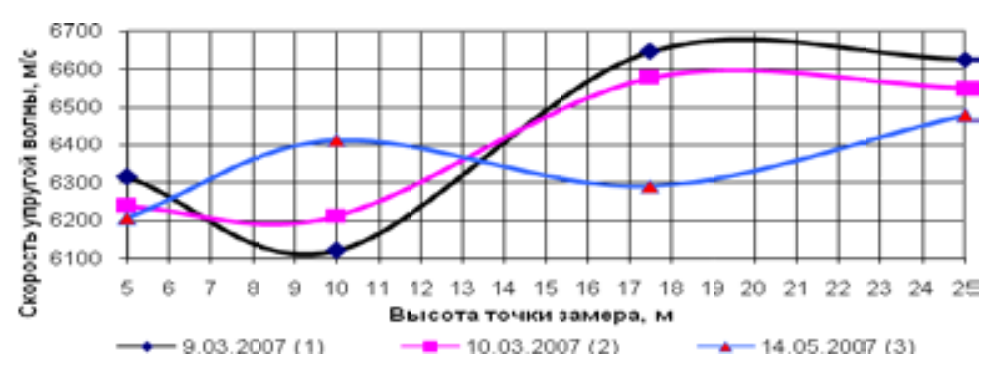

Рис. 2. Изменение скорости упругой волны в зависимости от высоты точки замера на борту карьера

В результате было установлено, что температура поверхности мрамора в карьере в течение года изменяется от минус 34 до $30,5^{\circ} \mathrm{C}$. Причем имеет место и пространственная вариация, особенно в зимний период. В шахте влияние температуры воздуха на пространственную вариацию температуры поверхности мрамора незначительно, а зимой зона отрицательных изотерм ограничивается только устьевой частью выработки.

В ходе исследований [2] было доказано, что при разности температур мрамора в зоне его резания (разность температур) более $113,6^{\circ} \mathrm{C}$ возможно его саморазрушение за пределами плоскости отделения. Поэтому чем больше ее величина, тем выше вероятность образования техногенных трещин, а следовательно, ниже выход блоков. В таком случае одинаковый выход блоков в карьере (ОГР) и шахте (ПГР) будет тогда, когда разности температур в обоих случаях будут 
близки. Для выявления таких условий построены графики временной динамики разности температур в карьере и шахте (рис. 3).

Из графика (рис. 3) видно, что в шахте и карьере разность температур примерно одинакова с апреля по октябрь. Именно в это время и средняя температура в приповерхностном слое мрамора в карьере на 10-12 градусов выше среднегодовой температуры поверхности мрамора в шахте. Следовательно, в это время наиболее целесообразно вести горные работы в карьере. Данное обстоятельство и предопределило целесообразность комбинированной разработки Кибик-Кордонского месторождения мрамора.

Для определения границы открытых и подземных работ использована методика раскроя месторождения мрамора на зоны открытых и подземных горных работ, в которой в качестве экономического критерия использован индекс доходности инвестиций (ИД). Методика позволяет дополнительно учитывать при раскрое месторождения сезонность работы карьера и вскрытие шахтного поля штольнями из бортов карьера.

Схемы раскроя месторождения показаны на рис. 4. Варианты границ раскроя ограничивались минимальной шириной дна карьера $\left(\mathrm{L}^{\mathrm{k}}{ }_{\mathrm{min}}\right)$ и шахтного поля $\left(\mathrm{L}^{\text {шin }}{ }_{\mathrm{min}}\right)$. Для реализации данной методики в программной среде Excel была разработана специальная программа.

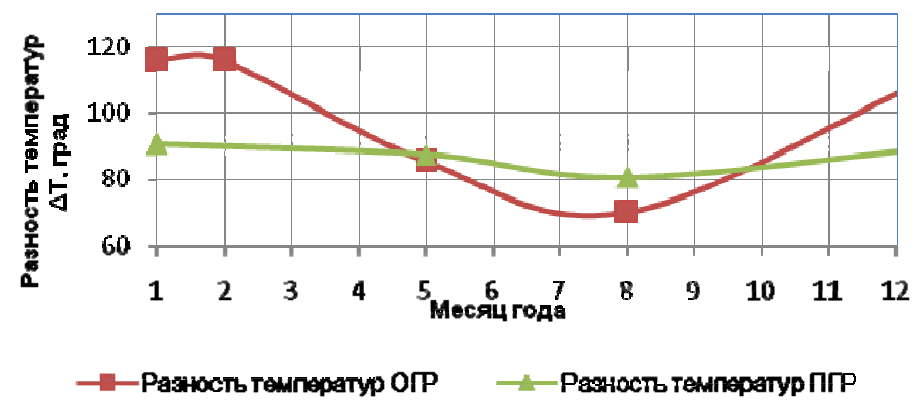

Рис. 3. Временная динамика разности температур в зоне пиления мрамора
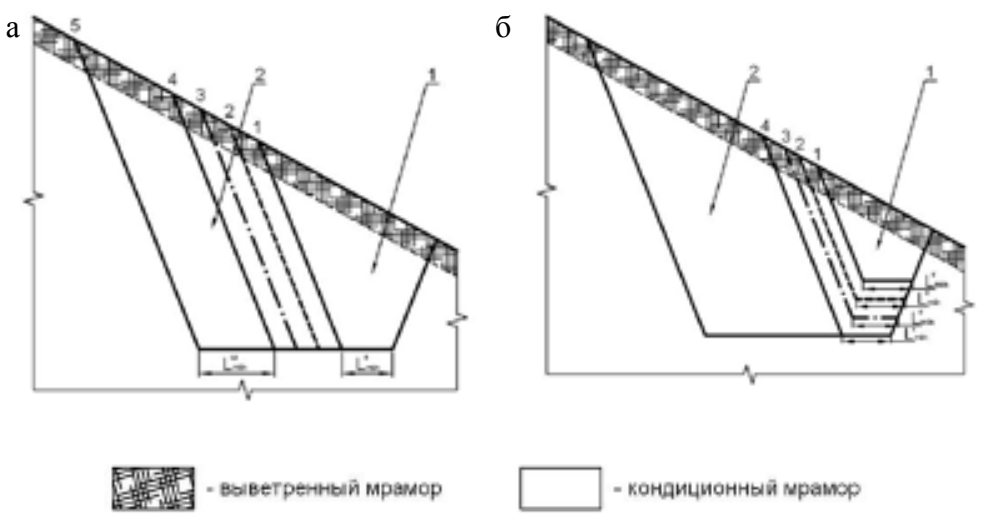

Рис. 4. Варианты раскроя месторождения мрамора при его разработке комбинированным способом при круглогодичной (а) и сезонной работе карьера (б): 1,2 - карьерное и шахтное поле; $1,2,3, \ldots 5$ - варианты границ раскроя 
Численные исследования, выполненные на ЭВМ, показали, что при сезонной работе карьера размеры шахтного поля должны быть значительно больше карьерного (рис. 4б). В рассмотренном примере доля открытого способа разработки не может превышать 30 \%. Причем возможны варианты отработки подкарьерных запасов только подземным способом (варианты 1, 2, 3 на рис. 4б). Графики, приведенные на рис. 5, подтверждают правомерность утверждения о целесообразности сезонной работы карьера при комбинированной разработке месторождения мрамора в условиях Сибири. Это позволит доходность инвестиций увеличить в 1,9-2,3 раза.

Комбинированный способ разработки месторождения предполагает ведение подземных и открытых горных работ при взаимозависимых (ВЗР3) и независимых рабочих зонах (НР3) (рис. 6).

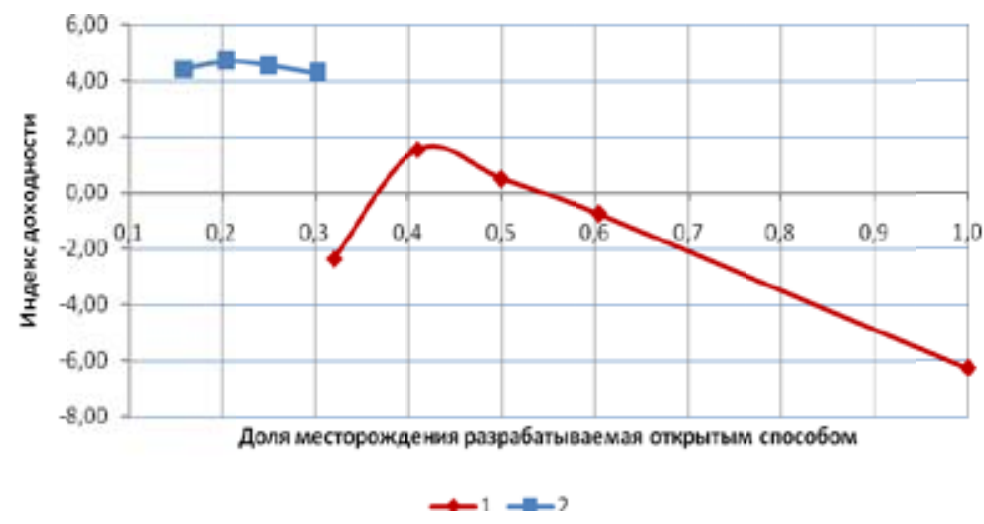

Рис. 5. Зависимость индекса доходности инвестиций от доли месторождения, разрабатываемого карьером при комбинированном способе: 1 и 2 - при круглогодичной и сезонной работе карьера

a

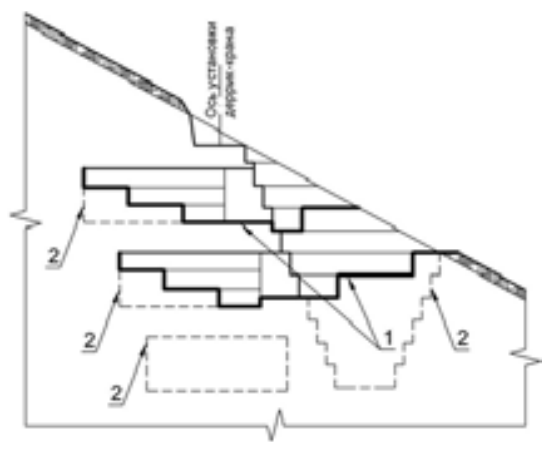

- выветренный мрамор
6

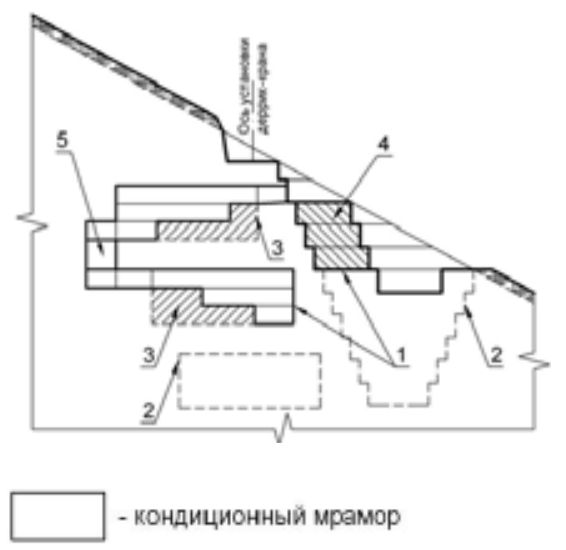

Рис. 6. Схемы комбинированной разработки месторождения мрамора с В3Р3 (а) и с НР3 (б): 1 и 2 положение горных работ в конце разработки; 3 - временные целики в шахте для размещения скользящих съездов; 4 - целик для размещения перегрузочной площадки; 5 - уклон 
Технологию комбинированной разработки с ВЗРЗ широко применяют при разработке мраморных месторождений Италии, где карьер напоминает ствол квадратного сечения с размерами сторон 50 м и более.

При ВЗРЗ открытых и подземных работ (рис. 6а) скорости понижения при различных способах должны быть одинаковыми. В результате общий объем добычи блоков ограничивается наименее интенсивным способом. В случае варианта разработки (рис. 6б) с НР3 и при сезонной работе карьера раскрой осуществляют, учитывая полную загрузку оборудования в течение года, и одновременной доработке месторождения открытым и подземным способом. Следовательно, в последнем случае будет достигаться большая производственная мощность при меньшем объеме инвестиций.

Неравенство в понижении горных работ может быть вызвано: малыми размерами шахты по сравнению с карьером; увеличением производительности на участках мрамора с разностями, пользующимися спросом на рынке камня; метеорологическими условиями местности и т.д.

Ведение горных работ с ВЗРЗ невозможно без остановки работ в шахте, связанных с выполнением подготовительных работ в карьере (для обеспечения врезки в соответствующий слой шахтного этажа по мере понижения горных работ в карьере).

Комбинированная разработка с независимыми рабочими зонами (НР3) обеспечивает независимую работу карьера и шахты, несмотря на то что шахтное поле вскрыто штольней из борта карьера.

Независимость рабочих зон возможно осуществить созданием перегрузочной площадки на временно законсервированных запасах мрамора в борту карьера. В данном случае независимость рабочих зон позволяет шахте в период сезонного простоя карьера продолжать работать, а также благодаря опережающему вскрытию нижних шахтных этажей разместить добычные комплексы, выводимые из карьера. Комбинированная разработка мраморного месторождения с НР3, имеющимся количеством выработок при минимальном объеме вспомогательных работ должна обеспечить грузотранспортную связь забоев с местами складирования блоков и окола. С этой целью предложено формировать перегрузочную площадку на временно законсервированных запасах мрамора в борту карьера, на которую с помощью колесных погрузчиков горную массу доставляют из шахты.

Для оценки реализации комбинированного способа разработки мраморных месторождений с НР3 при штольневом вскрытии шахтного поля из бортов карьера с использованием перегрузочных площадок смоделировали на ЭВМ в графической программе пространственные условия, отражающие особенности разработки нагорного месторождения мрамора от начала до завершения разработки месторождения. По своим параметрам и производительности электронная модель рудника соответствует реально существующему руднику «Доверие», строящемуся для разработки 1-го и 2-го литологических горизонтов Кибик-Кордонского месторождения мрамора.

При этом вначале (рис. 7а) к месту установки деррик-крана (1) проходят полутраншею (2), затем с рельефа нарезают площадку для проходки вскрывающей (3) и вентиляционных штолен (4). Возле устья штольни оставляют площадку (5) с размерами, необходимыми для маневрирования погрузчика и размещения блоков и окола, а слева и справа от нее ведут добычу блоков 
a

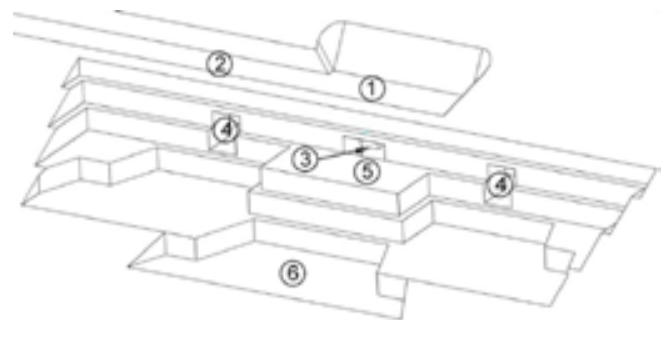

б

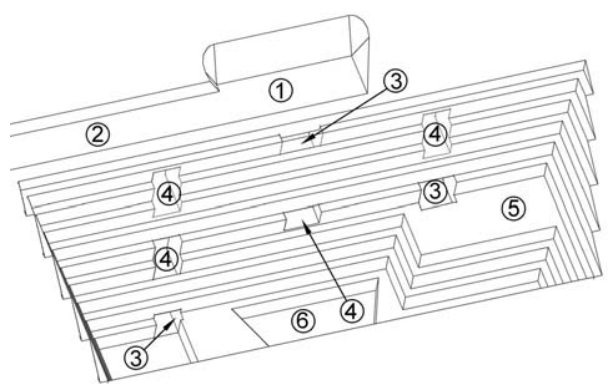

Рис. 7. Принципиальная схема формирования перегрузочной площадки (а) при разработке первого и (б) второго этажей: 1 - площадка для установки деррик-крана; 2 - вскрывающая полутраншея; 3 - вскрывающая штольня; 4 - вентиляционная штольня; 5 - перегрузочная площадка; 6 - карьер

открытым способом. Эта площадка ограничивает размеры целика временно законсервированных запасов. Разработку месторождения подземным способом ведут уступами высотой до 6 м, с делением на 1,5- или 2-метровые подуступы, применяя канатно-алмазные пилы или баровые машины.

Следующая перегрузочная площадка формируется в карьере на отметке выхода штолен из шахты в борт карьера (рис. 7б). Моделирование показало, что высоту целика для перегрузочной площадки рационально ограничивать величиной, равной сумме высот этажа и мощности междуэтажного целика. В данном случае при высоте этажа 18 м и мощности межэтажного целика 10 м высота консервируемого целика мрамора составит 28 м.

За счет этого подземные горные работы можно вести независимо от карьера, но при этом каждый подземный этаж должен иметь вентиляцию и выход на поверхность или в карьер. Для этого предложен следующий порядок вскрытия и отработки второго и последующих этажей. Вначале с почвы первого этажа вдоль шахтного поля проходят уклон (рис. 8) на отметку почвы первого уступа второго этажа. Затем из этого положения по шахтному полю проходят горизонтальные выработки, обеспечивающие по короткому плечу выход к месту устройства следующей перегрузочной площадки в карьере. Выработка, непосредственно выходящая на перегрузочную площадку, является вскрывающей. Далее фронт горных работ в шахте развивают от нее к флангам шахтного поля с опережающим продвижением забоев вблизи границы карьерного поля. Такое развитие позволяет в кратчайшие сроки пройти еще две вентиляционные выработки на флангах месторождения и осуществлять при необходимости одновременную работу на двух этажах. До момента выхода открытых работ на отметку выработок, пройденных из шахтного поля в карьер, горную массу доставляют из шахты колесными погрузчиками на перегрузочную площадку. После этого можно начинать работы по отработке целика, на котором размещалась перегрузочная площадка. Далее, используя систему скользящих съездов, интенсивно понижают горные работы в одной части шахтного поля для проходки подземных выработок, обеспечивающих вскрытие следующего этажа.

При комбинированной разработке мраморного месторождения в суровых климатических условиях его раскрой на зоны открытых и подземных работ следует осуществлять, учитывая сезонную работу карьера и независимость ведения работ различными способами. 


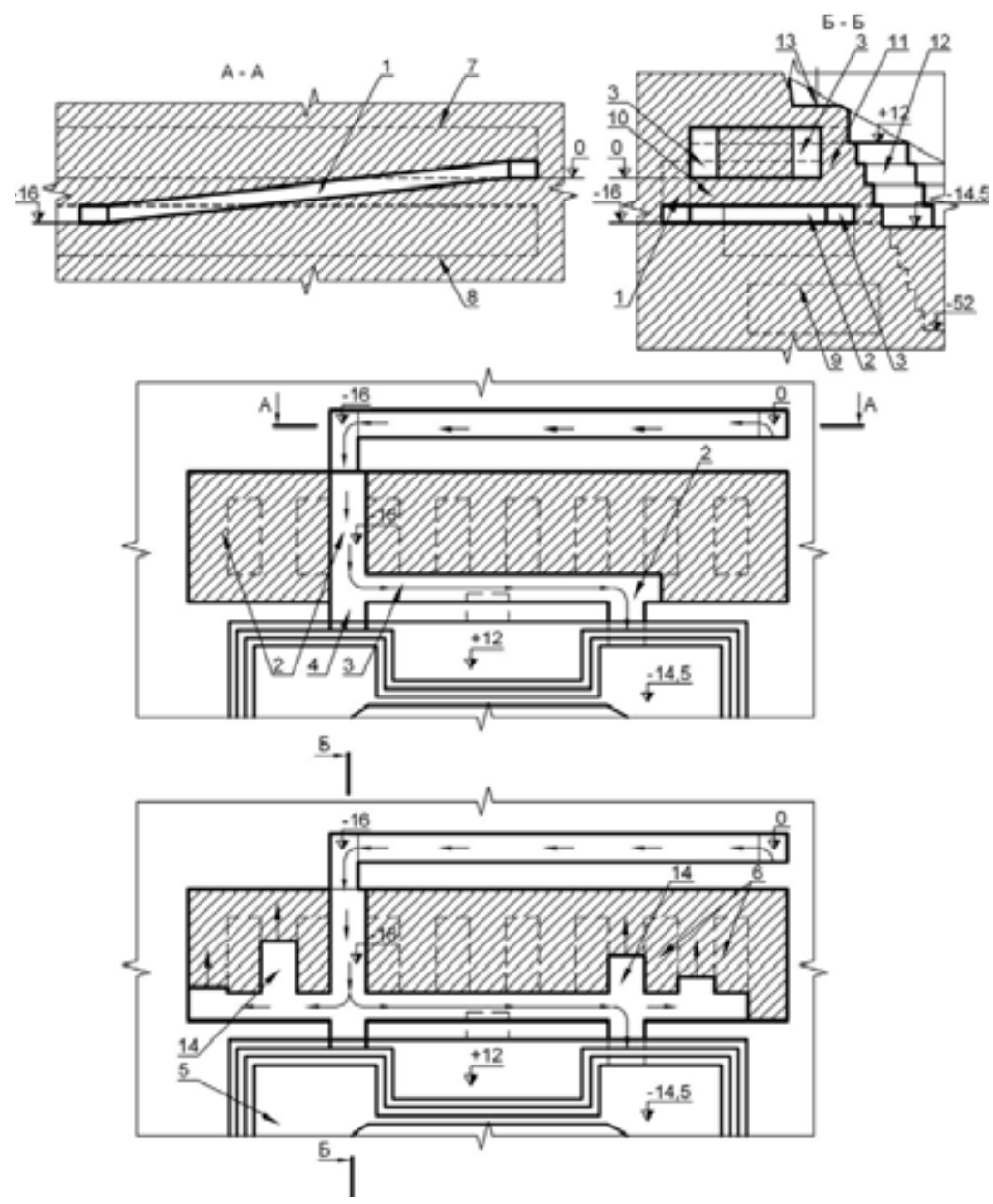

Рис. 8. Принципиальная схема вскрытия второго и последующих этажей: 1 - уклон; 2 и 3 - квершлаг и штрек; 4 - штольня; 5 - карьер; 6 - межкамерный целик; 7, 8 и 9 - границы первого, второго и третьего этажей; 10 и 11 - межэтажный и барьерный целики; 12 - временно законсервированные запасы мрамора; 13 - площадка для размещения деррик-крана; 14 - добычная камера

Комбинированная разработка месторождения мрамора независимыми рабочими зонами (НР3) при сезонной работе карьера по сравнению с взаимозависимыми рабочими зонами (ВЗР3) и круглогодичной работой карьера обеспечивает рост объемов добычи блоков и снижение удельных эксплуатационных и капитальных затрат.

Резюмируя вышеизложенное, следует сказать, что при комбинированной разработке месторождения мрамора:

- для обеспечения независимости рабочих зон открытых и подземных работ в борту карьера возле устья вскрывающей штольни необходима перегрузочная площадка для грузотранспортной связи шахты с поверхностью;

- рациональная продолжительность сезона работы карьера предопределена временной динамикой температуры воздуха и поверхности мрамора. 


\section{Список литературы}

[1] Косолапов А.И. Исследование и обоснование технологии разработки нагорных месторождений облицовочного мрамора: автореф. дис. ... д-ра техн. наук. М.: МГГУ, 1993.

[2] Косолапов А.И., Кадеров М.Ю. // Горный информационно-аналитический бюллетень. М.: МГГУ, 2008. № 4. С. 349-352.

[3] Косолапов А.И. // Горный журнал. 2011. № 5. С. 11-14. 